\title{
Road Traffic Accidents: An Unpremeditated Crisis Among School Students
}

\author{
Heaven Dahiya \\ Master of Science in Nursing, College of Nursing, Pt. B D Sharma Post Graduate Institute of Medical Sciences, \\ Rohtak, Haryana
}

\section{Introduction}

"It is better to lose one minute in life....then to lose life in a minute"

World Health Organization Advisory Group (1956), "Accident is defined as an unpremeditated event resulting in recognizable damage". Road Traffic Accident can be defined as "An event that occurs on a way or street open to public traffic resulting in one or more persons being injured or killed, where at least one moving vehicle is involved". According to The Global status report on road safety 2015, reflecting information from 180 countries, indicates that worldwide the total number of road traffic deaths has plateaued at 1.25 million per year, with the highest road traffic fatality rates in low-income countries. Only 28 countries, representing 416 million people (7\% of world population) have adequate laws that address all five behavioral risk factors (speed, drink driving, helmets, seat belts and child restraints). In India, the motor vehicle population is growing at a faster rate than the economic and population growth. Road accidents have earned India a dubious distinction. With over 130,000 deaths annually, the country has overtaken China and now has the worst road traffic accident rate worldwide.

In India, Every $10^{\text {th }}$ bed in the hospital is occupied by an accident victim.

Road traffic accidents are a human tragedy. They involve high human suffering and socio economic costs in terms of premature death, injuries, loss of productivity and so on. They are one of the main causes of death and injury to children of school age. Accidents tragically are often due to ignorance, carelessness, thoughtlessness and over confidence. The consequences of accident affect seriously the children's growth and development, interferes in their studies and future. Globally $26 \%$ of road traffic injury deaths were among children and adolescents under the age of 15 years. Motorcycle crashes are the leading cause of mortality and morbidity among teenagers. The world report on road traffic accidents were well on their way to become third leading cause of global death and disability by the year 2020 ahead of malaria, TB, HIV/AIDS. In 2010 a United Nations General Assembly resolution proclaimed a "Decade of Action for Road safety 2011-2020" launched in May 2011 in over 110 countries, with the aim of saving millions of lives by improving the safety of roads and vehicles, enhancing the behavior of road users and improving emergency services. WHO declared year 2004 as 'Year of Road Safety' with a slogan

\section{"It is better to lose one minute in life....then to lose life in a minute"}

World Bank Report (2012) Although India has only 1\% of the world's motor vehicles but it accounts as high as $6 \%$ of the World's road traffic accidents. Road traffic injuries is the $6^{\text {th }}$ leading cause of death in India with a greater share of hospitalization, death, disabilities and socio-economic losses in young and middle aged population. Road traffic injuries also place a huge burden on health sector in terms of pre hospital and acute care and rehabilitation.

WHO (2009) 73\% of deaths due to RTAs from the South-East Asia Region are in India. RTAs account for 16.8 deaths per 100,000 population and around 2 million people in India are disabled due to RTAs. "Road Accidents in India" an annual publication of the Transport Research Wing of Road Transport and Highways, Government of India is the nodal agency for providing information on various aspects of road accidents in the country during the calendar year, with main focus on adoption of a multi pronged strategy to address the issue of road safety based on 4Es of Road Safety.

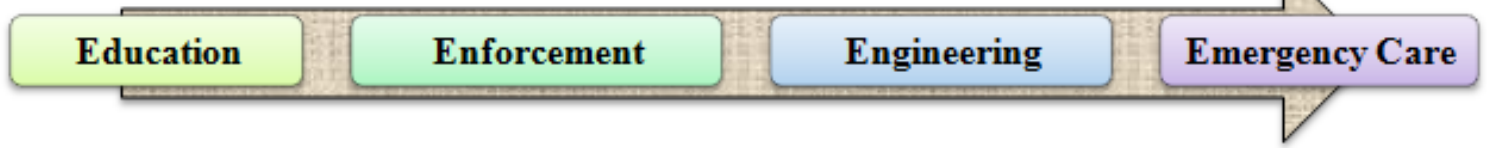

"Arrive SAFE", an Indian NGO is a project to preserve human life to make people get back home safe because we know roads can kill or maim...."Arrive SAFE" supports Decade of Action for Road Safety 20112020 by working on developing road safety programs to increase knowledge, awareness and skills amongst all types of road users. 
State Traffic Police Report (2011) found that Haryana ranks no 10 in the country as far as road mishaps are concerned. Around 1100 road accidents take place every year in Haryana. Haryana was the first Indian State that established Haryana Highway Patrol for Road Safety on with a mission "Safer Roads, Safer People". Margdarshan "New Hope, New Way - Devotion to Road Safety", NGO is also working for promotion of road safety in Haryana. With increasing road accidents in the state becoming a major cause of concern the Haryana Police has now started running a special awareness campaign across the state to make the school children aware about the traffic rules. As many as 14712 students of 1890 schools located in 4 districts - Rohtak, Jhajjar, Sonepat and Panipat of Rohtak Police Range took part in quiz contest on Road Safety wherein questions regarding traffic rules \& road safety were asked so as to make the students aware about traffic rules and regulations.

Shape the Future of Life, Healthy Environments for Children.

The Children of Today are the Adults of Tomorrow.

They deserve inherit a safer, fairer, healthier World.

There is no task more important than safe guarding their environment.

Our children can grow up to realize both their human rights and their full potential for health and productivity.

The problem of traffic accidents gets aggravated due to wide variety of slow and fast moving vehicles all moving at the same time without following any traffic rules. A study in India found that $20 \%$ to $30 \%$ of traffic violations occurred among drivers less than 20 years of age, with more than a third of these drivers either unlicenced or having obtained a licence without taking a mandatory test. Cognitive processes taking place in an adolescent's brain could affect their risk of road traffic crash as young drivers. Through the use of brain-imaging techniques, neurobiological research conducted over the past decade has found that parts of the frontal lobe-in particular the prefrontal cortex which governs judgement, decision-making, reasoning and impulse controlappears not to fully mature until the age of 20-25 years. While research linking this new evidence on brain development directly to driving has yet to be undertaken, these findings provide some insight into the biological mechanisms that may put many young at risk.

Salve S. B, Dase R. K et al. (2014) A study on awareness and behavior of adolescents towards road traffic accidents was carried out in urban field practice area of Mahatma Gandhi Mission Medical College Aurangabad, Maharashtra, India during the period Jan 2013 to March 2014 and it was concluded that the percentage of road traffic accidents was high i.e. 219 (68.44\%) amongst boys due to risk taking behavior like driving with triple seats, performing stunts, over-limit speeding etc.

The Hindu: Mobile Edition (2014) Nearly 50\% of those fined by transport authorities from January for driving without licence are students. On several occasions, school students have been reprimanded for riding motorbikes of their parents to attend morning tuitions. Racing is becoming popular among students on the highways, particularly on Sundays, Authorities say.

Glendon et al. (2014) A recent evaluation of one day school based program was undertaken by researchers from Griffith University. The school based intervention they evaluated among senior secondary students by comparing their attitudes and risk perception with a control group from another school. The result showed that the program had no effect on the student's risk perceptions. Singh R K, Gupta K et al. (2013) A prospective study on road traffic accidents was conducted from $1^{\text {st }}$ March 2012 to $30^{\text {th }}$ May 2012 at the Trauma Centre of King George's Medical University, Lucknow, India. The study suggested that concluded that the development of road policies and their strict implementation can reduce the severity and burden of injuries in India. There is a need for development based laws as each area has a unique pattern of traffic.

Singh Abhishek, Bhardwaj Anu et al. (2011) Cross-sectional study was carried at Maharishi Markandeshwar Institute of Medical Sciences and Research, Mullana, Ambala on all the victims who reported emergency and various OPD clinics of the Institute between September 2009 to February 2011. Majority of the RTA victims were in the age group of 15 to 50 years (79.47\%). 16.24\% of drivers did not have a valid driving licence. Not using indicator lights and not following speed limits were two most common factors responsible for Road Traffic Accidents.

C K Priyanka Raj et al. (2011) A school based cross-sectional questionnaire based study was conducted among 485 high school students in Anaichikuppam area of Villupuram district In Tamil Nadu (Nov 2010 to Jan 2011). Study revealed poor knowledge of traffic rules and unsafe traffic behavior among the school children.

Manna N, Mallik S et al. (2010) Descriptive, cross-sectional, hospital based prospective study was conducted in a tertiary care setting in Kolkata, India from Jan to June, 2010. The study highlighted interaction of several factors like lack of experience of drivers, low awareness of safety measures, narrow, broken and ill-illuminated roads, excessive speed with overloaded vehicles responsible for road traffic accidents. Kumarswamy et al. (2009) In a study from Southern India, 30\% of maxillofacial trauma in persons less than 16 years of age was because of road traffic accidents. 
Ministry of Home Affairs, Government of India (2009) Road Traffic Accidents rank fourth among the causes of deaths in 15-24 year age group accounting for 7\% deaths in this age group in rural India.

H. M. Swami et al. (2009) In this study, 8 schools (4 Government and 4 Private) were chosen randomly. From $9^{\text {th }}$ to $12^{\text {th }}$ classes students were selected using systemic random sampling method. Result showed that around $60 \%$ school children had correct knowledge of risk factors. The awareness was almost same in both government and private school as well as in males and females students. Majority of these children (70\%) had been driving since the age of 12 years and that too without proper licence to drive.

\section{Conclusion}

"Teach Children how they should live, they will remember it all their lives"

Road Safety being a multi- sectoral and multi - dimensional issue calls for cooperation/association of those who value human life more than vehicles. Small efforts made by those who feel concerned for the safety of road users will go a long way in reducing colossal loss of human lives and property. Now-a-days almost every school children is handling motor vehicles and incidence of road traffic accidents are also increasing year by year. Researchers suggested that it is important to understand and provide guidance to the students at the early stage of life regarding road safety and its education must begin with school children. School Health Nurse must encourage school authority to enroll road safety education as a part of school curriculum. Educational programmes should be conducted among the teenagers for the promotion of their health and safety in the road environment. It has been aptly said that -

"If Accident is a Disease, Education is its Vaccine"

\section{References}

[1]. Park K. Textbook of Preventive and Social Medicine. 22 ${ }^{\text {nd }}$ Ed. Bhanot. 2009; 374

[2]. RTA Report 2011-Epidemiology of Road Traffic Accidents in India: a Review of Literature. Sir Ratan Tata Trust; 2011. [Online]. 2006 [cited 2011]. Available from: http//:www.youthforroadsafety.org/uploads/nieuws_bijlagen/rta_report.pdf.

[3]. State Traffic Police Report 2011-47000 dead in Haryana road mishaps last year. Chandigarh: The Indian Express Limited; 2011. Available from: http://www.archieve.indainexpress.com/news/47000-dead-in-haryana-road-mishaps-last-year/79543412.

[4]. Salve S.B, Dase R. K, et al. A study on awareness and behavior of adolescents towards road traffic accidents. International Journal of Current Medical and Applied Sciences. 2014; 4(1):33-40. Available from: http://www.ijcmaas.com/pdffileDownload?id=78.

[5]. The Hindu: Mobile Edition 2014-Students override all road safety rules. The Hindu; 2014. [Online].2014 [cited 2014 Nov 6]. Available from: http://www.thehindu.com/news/cities/Madurai/students-override-all-safety-rules/articles6570293.ece/.

[6]. Glendon A., Mc Nally B., et al. Evaluating novice driver and pre-driver road safety intervention. Accident analysis and prevention. 2014; 64:100-110.

[7]. Singh R K, Gupta K, et al. Elucidation of risk factors in survivors of road traffic accidents in North India. Hard Tissue. 2013 ; 2(1):1. Available from: http://www.oapublishinglondon.com/article/304\#.

[8]. Singh Abhishek, Bhardwaj Anu, et al. An Epidemiological study of road traffic cases at a tertiary care hospital in rural, Haryana. Indian Journal of Community Health. 2011; 23(2). Available from: http:/ /www. iapsmupuk. org/journal/ index. php/ IJCH/ article/ view/ 47/html-1.

[9]. Priyanka C K, Datta Shib Shekhar, et al. Study of knowledge and behavioral pattern with regard to road safety among high school children in a rural community in Tamil Nadu. Indian Journal of Medical Specialities; 2011.

[10]. Manna N, Mallik S, et al. The epidemiological factors of road traffic accidents: A study in a tertiary care setting. Journal of Pioneering Medical Sciences. 2013; 3(1):48-53. Available from: http://www.jpmsonline.com/jpms-vol3-issue/-pages48-53.oa.html.

[11]. Swami H.M, Puri S, Bhatia V. Road safety awareness and practices among school children of Chandigarh. Indian Journal of Community Medicine. 2009; 31(3):200-207. 